\title{
ASPECTOS DIFERENCIAIS ENTRE COESÃO E FRAGMENTAÇÃO NAS OBRAS DE ELIAS E GUIZOT: UMA ANÁLISE PARA A EDUCAÇÃO DA SOCIEDADE CONTEMPORÂNEA
}

\author{
Maria do Carmo Gonçalves da Silva Lima (D1 e Giovana Cardoso Versolatto (D2
}

\section{Resumo}

O presente estudo tem como objetivo analisar os aspectos diferenciais entre elementos que constituem coesão e fragmentação na obra Os estabelecidos e os outsiders de Norbert Elias (2000) e História da Civilização na Europa de François Guizot (1907) e, a partir das análises feitas, tecer relações entre os aspectos diferenciais nas obras desses autores e a educação na sociedade contemporânea. Norbert Elias faz uma análise acerca do alto índice de delinquência juvenil na comunidade de Winston Parva e percebe que o fator de fragmentação entre os moradores do local e a coesão inflexível existente entre os antigos residentes do bairro, decorre na ausência de coesão entre os recémchegados ao bairro, que não dispunham de relações sociais mais antigas para se defenderem das acusações dos estabelecidos. Em Guizot, verificamos que para a constituição de uma civilização, se fazia necessário a coesão da sociedade civil aliada ao desenvolvimento da vida individual. Compreendemos que na sociedade contemporânea, ocorre a valorização exacerbada das questões individuais, em detrimento das relações sociais coletivas, que visa o bem-estar comum para o desenvolvimento integrado da sociedade como um todo. Diante disso, consideramos que o estudo do entendimento que os homens faziam da sociedade de seu tempo, é primordial para compreendermos as questões que determinam as relações sociais do presente século.

Palavras-chave: História; Civilização; Século XXI.

\section{DIFFERENTIAL ASPECTS BETWEEN COHESION AND FRAGMENTATION IN THE WORKS OF ELIAS AND GUIZOT: AN ANALYSIS FOR THE EDUCATION OF CONTEMPORARY SOCIETY}

\begin{abstract}
The present study aims to analyze the differential aspects between elements that constitute cohesion and fragmentation in the work The established and outsiders by Norbert Elias (2000) and François Guizot's History of Civilization in Europe (1907) and, based on the analyzes made, weave relations between the differential aspects in the works of these authors and education in contemporary

${ }^{1}$ Doutoranda em Educação, pela Universidade Estadual de Maringá, docente da Rede Municipal de Ensino de Maringá, PR. Integrante do Laboratório de Estudo sobre o Império Português - LEIP/UEM.

${ }^{2}$ Doutoranda em Educação, pela Universidade Estadual de Maringá, integrante do Laboratório de Estudo sobre o Império Português - LEIP/UEM.
\end{abstract}


society. Norbert Elias analyzes the high rate of juvenile delinquency in the community of Winston Parva and realizes that the fragmentation factor among local residents and the inflexible cohesion that exists among former residents of the neighborhood, stems from the absence of cohesion among newly arrived in the neighborhood, who had no older social relationships to defend themselves against the accusations of the established. In Guizot, we found that for the constitution of a civilization, the cohesion of civil society coupled with the development of individual life was necessary. We understand that in contemporary society, there is an exaggerated valuation of individual issues, to the detriment of collective social relations, which aims at the common well-being for the progress and development of society as an integrated whole. Therefore, we consider that the study of the understanding that men made of the society of their time, is essential to understand the questions that determine the social relations of the present century.

Keywords: History; Civilization; XXI Century.

\section{Introdução}

Nesta pesquisa, temos como objetivo analisar os aspectos diferenciais entre os elementos que constituem a coesão e a fragmentação na sociedade, especificamente na comunidade pesquisada por Norbert Elias (2000) e na ideia de civilização defendida por François Guizot (1907). Nesse sentido, analisamos as propostas educativas para a sociedade contemporânea, sob a perspectiva de Elias que considera estarem sociedade e indivíduo inter-relacionados, ou seja, devemos levar em consideração, que a sociedade não está separada do indivíduo, mas ambos os conceitos estão inter-relacionados como um todo integrado. Verificamos também em Guizot, a defesa da integração entre desenvolvimento da sociedade civil e desenvolvimento do homem individual, ou seja, vida coletiva e individual como um todo integrado.

Consideramos que o ideal de coesão para o desenvolvimento da sociedade do século XXI tem se perdido diante do esfacelamento das relações comunitárias e do isolamento crescente dos indivíduos sociais. De modo geral, o foco reside no âmbito individual e na prevalência de questões particulares, em detrimento de qualquer relação às questões exteriores aos sujeitos. Diante disso, a sociedade torna-se absorta das causas públicos e desinteressada em alcançar um denominador comum para as questões relacionadas ao coletivo.

Segundo aponta Sinésio Bueno (2013), partindo dos pressupostos da teoria crítica, os conceitos de diversidade, pluralidade e individualismo têm sido basilares na formação da sociedade contemporânea. E isto posto, cabe aos sistemas educativos a responsabilidade de lidar com o fenômeno da diversidade, e também, com a preservação da homogeneidade entre os grupos distintos para a manutenção da sociedade, no sentido de construir um entendimento sobre coesão em meio as diferenças.

Dessa forma, procuramos responder a seguinte questão: Como os conceitos de coesão e civilização de Elias (2000) e Guizot (1907) colaboram com 
a compreensão sobre a concepção da coletividade em nossa atual sociedade fragmentada?

Para responder a esta questão, buscamos a fundamentação teórica em Guizot (1907), Elias (2000), Bueno (2013) e demais pesquisadores que nos auxiliaram a entender a concepção de coesão e fragmentação no desenvolvimento da sociedade. Assim, este estudo justifica-se por entendermos que a compreensão dos elementos que constituíram a sociedade no passado, nos serve de orientação para compreendermos o nosso presente social e educativo, na busca por respostas para as questões que envolvem a sociedade do século XXI.

\section{A ideia de coesão e fragmentação na obra os estabelecidos e os outsiders}

A obra Os estabelecidos e os outsiders (2000) trata-se de um estudo realizado na comunidade de Winston Parva (nome fictício), próxima de Leicester, na Inglaterra no final da década de 1950 e início de 1960, pelo professor John L. Scotson, interessado em tratar da delinquência juvenil e das relações de poder na comunidade daquela localidade.

Norbert Elias trouxe outras perspectivas ao estudo reelaborando-o, de maneira a esclarecer processos sociais de alcance geral na sociedade, "[...] inclusive a maneira como um grupo de pessoas é capaz de monopolizar as oportunidades de poder e utilizá-las para marginalizar e estigmatizar membros de outro grupo muito semelhante" (ELIAS, 2000, p. 13).

A pequena comunidade de Winston Parva tinha por núcleo um bairro antigo e, ao redor dele, dois bairros mais recentes. O interesse pelo estudo na comunidade surgiu porque um dos bairros tinha índice de delinquência mais elevado do que os outros bairros. O objeto da pesquisa modificou-se quando observado por Elias (2000), que o nível de delinquência havia diminuído, mas outros aspectos se mostraram presentes: uma relação de poder entre as antigas famílias de moradores do vilarejo sob as recém-chegadas.

Elias (2000) relata que ao investigar os fatos e buscar explicações para o alto índice de violência no bairro, os investigadores se depararam com as diferenças nas relações entre os moradores. Assim, de um problema associado à delinquência juvenil, os pesquisadores foram levados a refletir sobre questões condizentes com a própria sociedade. No centro de suas discussões estavam as relações de poder e de status no interior da comunidade. A investigação os levou a buscar explicar o porquê das relações de poder e status causadoras de divergências entre os moradores.

Nesse sentido, o estudo que visava compreender o problema da delinquência juvenil em um bairro, passou para o estudo de um problema mais amplo na sociedade. Para Elias (2000, p. 16): 
[...] a pesquisa indicou que os problemas em pequena escala do desenvolvimento de uma comunidade e os problemas em larga escala do desenvolvimento de um país são inseparáveis. Não faz muito sentido estudar fenômenos comunitários como se eles ocorressem num vazio sociológico.

A comunidade mais antiga de Winston Parva sentiu-se incomodada pelo desenvolvimento de uma área industrial construída no bairro. No período da $2^{a}$ guerra mundial, um grande número de operários estabeleceu-se no local juntamente com a fábrica. Para os moradores que já residiam na comunidade, e que haviam fixado uma vida comunitária estável, com tradições próprias do grupo, viam-se diante do fato de que chegava um número maior de pessoas para se estabelecer em suas imediações, pessoas que até certo ponto, tinham ideias, maneiras e crenças diferentes das que eram costumeiras e valorizadas pelos pioneiros de Winston Parva.

Diante disso, o núcleo dos residentes antigos atribuía um valor elevado aos padrões, às normas e ao estilo de vida que eles haviam criado entre si. Tudo isso tinha uma estreita ligação com seu respeito próprio e com o respeito que eles julgavam ser-lhes devido pelos outros. A ascensão de uma minoria, para o nível de classe média, exercia um poder considerável na antiga comunidade. $\mathrm{E}$ esse poder que os antigos moradores possuíam era motivo de orgulho para a maioria dos residentes mais antigos e não admitiam que outro grupo estivesse no mesmo padrão de vida em que estavam.

Os novos não tinham intenção de perturbar os antigos residentes do bairro. No entanto, foram vistos como uma ameaça à ordem existente porque os antigos moradores achavam que qualquer contato com eles rebaixaria seu próprio status, e que reduziria o prestígio de seu bairro. Nesse sentido, os recém-chegados foram vistos como uma ameaça pelos antigos moradores.

Elias (2000) esclarece que o grupo estabelecido atribuía aos seus membros características humanas superiores, excluindo todos os membros do outro grupo. O distanciamento entre as pessoas era mantido por meio de controle social, como a fofoca elogiosa entre os antigos residentes, e fofocas depreciativas contra os outsiders. As fofocas colocavam os recém-chegados sob um prisma desfavorável e confirmava a superioridade da moral e dos costumes dos velhos residentes.

Os outsiders vivenciavam afetivamente sua inferioridade de poder como um sinal de inferioridade humana. Estigma, preconceito e o medo do contágio reforçavam o tabu imputado aos outsiders, que não dispunham de nenhuma possibilidade de revidar o grupo estabelecido com os mesmos termos depreciativos que recebiam como desordeiros das leis e normas.

Elias (2000) afirma que a delinquência juvenil passou a ser uma manifestação de reação por parte dos jovens do loteamento diante da exclusão e coerção que recebiam dos estabelecidos. Assim, para manifestar o sentimento de inferioridade social enraizado desde a sua infância e nas inter-relações com as outras crianças de sua comunidade, os jovens passaram à prática de atos de 
vandalismo. Para Elias (2000, p. 19) a comunidade de Winston Parva representava um tema humano universal.

Essa é a autoimagem normal dos grupos que, em termos do seu diferencial de poder, são seguramente superiores a outros grupos interdependentes. Quer se trate de quadros sociais, como os senhores feudais em relação aos vilões, os "brancos" em relação aos "negros", os gentios em relação aos judeus, os protestantes em relação aos católicos e vice-versa, os homens em relação às mulheres (antigamente), os Estados nacionais grandes e poderosos em relação a seus homólogos pequenos e relativamente impotentes $[\ldots]$.

No entanto, na pequena comunidade de Winston Parva, entre os recémchegados e os antigos residentes, não havia diferenças de nacionalidade, cor ou raça, ascendência étnica ou religião. Tão pouco diferiam quanto ao trabalho que ocupavam, renda e nível educacional, ou seja, os moradores pertenciam a mesma classe social. A única diferença apontada por Norbert Elias estava no tempo de moradia entre os moradores do bairro.

A coesão do grupo estabelecido se dava por meio das diferentes relações estabelecidas entre as pessoas da vizinhança. "A inclusão na coletividade estava ligada à vida e às tradições comunitárias" (ELIAS, 2000, p. 25). As interdependências construídas pelos moradores no trabalho, nos negócios, nos espaços sociais, fortaleceram as relações dos antigos membros do bairro, de modo que passaram a se ver como melhores e superiores aos novos vizinhos.

Ali, podia-se ver que a "antiguidade" da associação, com tudo o que ela implicava, conseguia, por si só, criar o grau de coesão grupal, a identificação coletiva e as normas comuns capazes de induzir à euforia gratificante que acompanha a consciência de pertencer a um grupo de valor superior, com o desprezo complementar por outros grupos (ELIAS, 2000, p. 21).

Diante disso, o grupo estabelecido lutava por superioridade, status e poder. Para Elias "o poder não é um amuleto que um indivíduo possua e outro não, é uma característica estrutural das relações humanas - de todas as relações humanas" (1980, p. 81). Uma vez que as relações humanas são multipolares, o poder que as perpassa não é uma ocorrência extraordinária e sim cotidiana, não está apenas nas grandes arenas da economia e da política, mas também nas pequenas ocorrências e configurações. O poder está no centro das inúmeras relações humanas. E, para a manutenção do poder e coesão entre os indivíduos, os estabelecidos utilizavam a fofoca humilhante, os estereótipos verbais degradantes, a exclusão e a estigmatização.

Os outsiders por sua vez, não reagiam as difamações no mesmo tom depreciativo, por sentirem-se realmente carentes de virtudes, julgando-se humanamente inferiores. Internalizavam as estigmatizações feitas pelos estabelecidos, reforçando a supremacia dos antigos moradores na comunidade, 
que respeitavam as regras, de não socializar ou ter contato íntimo com os novos moradores da cidade, e de não Ihes atribuir características positivas, pela satisfação de pertencerem a um grupo superior.

Para Elias (2000, p. 24) havia uma acentuada diferença na coesão entre os dois grupos: "Um grupo era estreitamente integrado, e o outro, não". Os diferenciais de poder estavam justamente nos diferenciais de coesão e integração dos indivíduos. "Os recém-chegados eram desconhecidos não apenas dos antigos residentes, mas também entre eles; não tinham coesão, e, por isso, não conseguiam cerrar fileiras e revidar" (ELIAS, 2000, p. 25). Assim, por não haver consonância entre os novos moradores, estes não dispunham de ferramentas para se defenderem contra as difamações dos estabelecidos. Percebe-se então que, no âmbito das relações de uma sociedade, para que haja sentimento de pertencimento ao grupo, neste deverá haver unidade, coesão, fortalecimento dos laços que trarão empecilhos para a fragmentação.

\section{A civilização em François Guizot: uma análise dos elementos de coesão na sociedade}

Ao retomarmos os aspectos defendidos por François Guizot (1907), na sua concepção universal da história ao tratar do conceito de civilização, percebemos que, para o historiador, no intuito de que um povo fosse civilizado, deveria existir o progresso e o desenvolvimento.

[...] desperta logo a ideia de um povo que caminha, não para mudar de lugar, mas para mudar de estado; de um povo cuja condição se desenvolve e se aperfeiçoa. A ideia do progresso, do desenvolvimento, parece-me ser a ideia fundamental contida sob a palavra de civilização (GUIZOT, 1838 apud OLIVEIRA, 1998, p. 126).

Nesse sentido, o progresso da civilização estaria no "[...] aperfeiçoamento da vida civil, o desenvolvimento da sociedade propriamente dita, das relações dos homens entre si [...]" (OLIVEIRA, 1998, p. 126). No entanto, Oliveira (1998) ainda esclarece que a definição de civilização não bastava apenas às relações sociais. "Existiria algo mais extenso, mais complexo: [...] é o desenvolvimento da vida individual, da vida interior, ou seja, o desenvolvimento do próprio homem, das suas faculdades, dos seus sentimentos e ideias." Assim, esses dois elementos estariam interligados, sendo ambos necessários para a constituição da civilização. A esse respeito, Guizot tece as seguintes considerações:

Parece-me que devemos assentar que, na convicção espontânea e instintiva do homem, os dois elementos da civilização, o desenvolvimento social e o desenvolvimento moral, andam intimamente ligados; que o gênero humano, vendo a um, espera logo ao outro. Recorre-se a esta convicção todas as vezes que para apoiar ou combater um ou outro d'estes desenvolvimentos, se afirma ou nega a sua união. Sabe-se que, persuadidos os homens de que o melhoramento do estado social é prejudicial ao progresso 
interno dos indivíduos, ficará desacreditada ou enfraquecida a revolução que se está produzindo na sociedade. Por outro lado sabe-se que, prometendo-se aos homens o melhoramento da sociedade, como consequência do melhoramento individual, a sua tendência é crer n'esta promessa, e d'isto muito se aproveitam os reformadores. Parece-me, pois, evidente ser crença geral da humanidade que estão intimamente ligados e nascem um do outro os dois elementos da civilização. (GUIZOT, 1907, p. 42).

Para a efetivação desses dois elementos, Guizot (1907), defendia o estabelecimento de um governo que os comandasse. Desse modo, ao "[...] permitir a convivência desses diferentes segmentos, o governo representativo seria a forma de governo que conservaria o desenvolvimento conjunto dos dois elementos fundamentais da sociedade" (OLIVEIRA, 1998, p. 127). Diante disso, podemos inferir que para Guizot (1907), para que houvesse o progresso e desenvolvimento da civilização se fazia necessário a coesão entre os dois elementos: aperfeiçoamento da vida civil e desenvolvimento da vida individual. Ainda, segundo o autor:

Quando se opera no homem uma alteração moral, quando adquire uma ideia, uma virtude, uma faculdade a mais, em uma palavra, quando se desenvolve individualmente qual é a necessidade que ele desde logo sente? É a de transmitir o seu sentimento ao mundo exterior, de realizar externamente o seu pensamento. [...]. Realiza-se a revolução no estado da sociedade; fica esta mais bem regulada, ficam mais igualmente repartidos os direitos e os deveres; apresenta-se mais puro e mais belo o especulo do mundo, melhoram na prática os governos, aperfeiçoam-se as relações entre os homens. E poderemos duvidar que a vista d'este especulo, que este melhoramento dos factos externos deixe de reagir sobre o homem interior, sobre a humanidade? Tudo quanto se alega acerca da autoridade dos exemplos, dos hábitos, dos bons modelos, funda-se exclusivamente sobre a convicção de que um fato exterior quando é bom, racional, bem regulado, produz mais cedo ou mais tarde, mais ou menos completamente um fato interno da mesma natureza e com o mesmo mérito; que sendo o mundo mais bem regulado e mais justo, é o homem mais justo também; que a reforma do interior opera-se por meio do exterior, e a d'este por aquele [...]. (GUIZOT, 1907, p. 43-45).

Para Guizot (1907) a mudança individual na vida dos homens provoca também mudanças na sociedade. Da mesma forma, as transformações ocorridas na sociedade também afetam os homens provocando novos comportamentos. Nesse sentido, indivíduo e sociedade não se separam, mas estão unidos e se refletem mutuamente.

Assim, nas obras de Norbert Elias e François Guizot, o fator coesão é elemento essencial para o progresso da sociedade. Todavia, devemos levar em consideração que os autores citados não trataram dessas questões do mesmo modo, pois os aspectos que estavam postos no momento histórico em que 
viviam eram outros e, portanto, não podemos cometer anacronismos. Em nossa análise buscamos refletir sobre o fato de que, tanto para Elias (2000) quanto para Guizot (1907), indivíduo e sociedade são elementos indivisíveis e estão intimamente ligados.

De acordo com os professores Célio Juvenal Costa e Sezinando Luiz Menezes (2013, p. 246), "Para Norbert Elias, a perspectiva social deve levar em consideração a não separação entre indivíduo e sociedade, tratando ambos os conceitos como se fossem dois aspectos inter-relacionados da trama social."

\section{Norbert Elias e François Guizot: uma análise para a educação da sociedade contemporânea}

Trazendo esses conceitos para a sociedade do século XXI, verificamos que o ideal de coesão para o desenvolvimento da sociedade, tem se perdido diante do esfacelamento das relações comunitárias e do isolamento crescente dos indivíduos na sociedade contemporânea. De modo geral, o foco reside no âmbito individual e na prevalência de questões internas, em detrimento de qualquer relação às questões exteriores aos sujeitos. Diante disso, a sociedade torna-se absorta das causas públicos e desinteressada das questões relacionadas ao coletivo.

O enfoque excessivo no âmbito individual modifica a relação com o outro, no sentido de enfraquecimento dos conflitos, pois na superficialidade das relações, as forças opostas tornam-se também superficiais, sem haver encontro real ou debates produtivos. Na busca por seu bem-estar e valorização exacerbada do eu, o indivíduo se fecha para o outro, para as questões sociais, e esse individualismo o enfraquece a tal ponto que os ideais comunitários deixam de ser relevantes. O que importa são suas necessidades presentes e imediatas.

Uma das consequências mais perceptíveis da individualização na sociedade contemporânea é a perda da concepção do homem como ser genérico. Ocorrendo assim, o abandono de qualquer perspectiva de totalidade e de um projeto social e político que aponte a superação da sociedade que está posta. De acordo com Elias (1980, p. 150), a nossa visão passa a ser mais completa se compreendemos "as interdependências pessoais e sobretudo as ligações emocionais entre as pessoas, considerando-as como agentes unificadores de toda a sociedade. E mesmo que o aglutinador da sociedade seja o indivíduo, nenhuma estrutura, seja ela um casamento ou um parlamento, deve ser explicada de forma isolada.

Entende-se o estudo da sociedade em camadas, no qual o eu está no centro e as demais esferas da sociedade o cercam. Para Elias (1980, p. 123), a partir de inclinações, os indivíduos estabelecem teias de interdependência ou configurações de vários tipos, que ao invés de os cercar, os permeiam: "os indivíduos só podem possuir características especificamente humanas tais como capacidades de falar, pensar, e amar nas e pelas suas relações com as outras pessoas em sociedade". 
Em uma tentativa de analisar a sociedade, temos a tendência de tratá-la como exterior ao indivíduo, no entanto, ela se faz presente em nós e por meio do encontro dos indivíduos e, portanto, não existe para além destes. Na percepção de Elias (1980), é um erro colocar indivíduo e sociedade como opostos, ambos estão vinculados em uma relação de interdependência. Esta desumanização do conceito de sociedade possibilita ao indivíduo um tipo de externalização dos fatos.

Tornou-se habitual utilizar forças exteriores a nós - naturais ou míticas como justificativas de nossos atos, como se algum "poder" nos compelisse a praticar algo do qual não temos controle. Contudo, Elias (1980) relata que o que é compreendido como uma força exterior que compele o sujeito, é a rigor, forças sociais exercidas pelas pessoas sobre outras e sobre elas próprias.

Segundo Elias (1980), o avanço tecnológico é um tipo de configuração à qual foi atribuído caráter autônomo extra-humano, por exemplo, a bomba nuclear passou a ser culpada pela destruição e extermínio que causou. No entanto, não são os avanços científicos, ou as bombas em si que devem ser temidos, mas sim as intenções das pessoas que estão conduzindo esses projetos por meio do avanço tecnológico. A falsa percepção de que as pessoas não estão no controle das configurações também se estende à linguagem, quando dizemos o jogo está muito lento isentamos o grupo de pessoas envolvidas no processo a respeito do tempo das jogadas.

Desta maneira, não é apenas uma questão conceitual a compreensão de que indivíduo e sociedade são interdependentes e não opostos, e sim, uma questão central, uma vez que possui consequências práticas em nosso cotidiano, desde sequelas significativas a efeitos banais. Elias também nos faz pensar sobre a contrapartida da noção de que os indivíduos estão no controle de absolutamente todas as configurações: "Existem interdependências humanas não intencionais, na base de todas as interações intencionais [...] do intercruzar das ações de muitas pessoas podem emergir consequências sociais que ninguém planejou" (1980, p.103), portanto, essa relação possui dois lados e nenhuma força poderosa exterior equilibrando-a. Organicamente os pensamentos adquiridos no nível dos fenômenos naturais passam a atribuir significados fantasiosos a realidades provocadas pela coexistência humana. Como quando, de acordo com Elias (1980), grupos convertem em fantasia a ansiedade e o medo do inexplicável, estendendo ao estrangeiro ou aos grupos socialmente mais vulneráveis a causa dos seus próprios sofrimentos.

A fixação mental em fenômenos familiares e tangíveis como bombas nucleares e máquinas, ou, num sentido mais lato, na ciência e na tecnologia, obscurecendo as causas sociais de medo de mal-estar, é sintoma de uma das características fundamentais da nossa capacidade relativamente grande de ultrapassarmos - de um modo adequado e realista - problemas causados por acontecimentos naturais extra-humanos, e, por outro, a nossa limitada capacidade de resolver com a mesma segurança os problemas da coexistência humana. (ELIAS, 1980, p. 26) 
Ao mesmo tempo que a singularidade de cada indivíduo deve ser considerada, é necessário levarmos em conta que a estrutura sociedade também obtém resultados, cujas consequência ninguém planejou. Entender esta dinâmica, possibilita que evitemos a culpabilização de uma esfera ou outra, mas passemos a tratá-las como um processo de interdependência. $E$ não de individualização, tais quais os produzidos por essa nova ordem de fragmentação social, em que cada grupo levanta uma bandeira diferente, no embate de diferentes causas e partidos, como na defesa cultural, étnica ou de gênero. Nesse sentido,

A diferença cultural, étnica ou de gênero, quando valorizada, mesmo que positivamente, porém sem a mediação do conceito de homem genérico ou universal, resulta empobrecida e fetichizada, podendo ser facilmente neutralizada justamente por aqueles que compartilham de preconceitos (BUENO, 2013, p. 237).

Como também, a luta pelo direito à igualdade cedeu lugar à luta pelo direito à diferença como um princípio ético, na defesa do relativismo cultural e do discurso que faz da diversidade e da desigualdade um princípio de respeito, valorização e igualdade.

O estudo sobre Winston Parva foi realizado no final da década de 1950 e início da década de 1960 e, segundo Wood (1999), nesta mesma época, exatamente em 1959, o sociólogo Wright Mills escrevia sobre o fim da era moderna e o nascimento da pós-modernidade. Isto significava que a esperança na razão, libertadora e elucidativa, era sucumbida por uma descrença profunda nos preceitos do Iluminismo. Wood afirma que não só Mills, mas outros intelectuais sentenciaram: "estamos vivendo em uma época "pós-moderna", que o "projeto do Iluminismo" está morto, que todas as antigas verdades e ideologias perderam sua relevância, que os velhos princípios da racionalidade não mais se aplicam" (WOOD, 1999, p. 10).

Conforme Hobsbawm (1998), após uma catastrófica história no século XX, de depressão, guerras, governos totalitários e de declínio em relação às normas morais estabelecidas tradicional e socialmente, houve um rompimento com os valores herdados do Iluminismo. Repercutindo em um estado de colapso, gerado pelos próprios agentes de decisão, os indivíduos da sociedade, que viam o mundo escapar por suas mãos, pois não sabiam lidar com as novas regras, ou a falta delas, para governar o comportamento das sociedades humanas.

Para Wood (1999), os pós-modernistas rejeitam categoricamente as verdades totalizantes, os conhecimentos universais e, em geral, as ideias advindas da racionalidade e igualdade. No lugar, há uma ampla abertura para as diferenças individuais, para as questões identitárias, como etnia, gênero, sexualidade e todas as lutas advindas das particularidades de cada uma destas ramificações, com seus conhecimentos compartimentados. O conhecimento humano e a compreensão de mundo dos pós-modernistas são essencialmente fragmentados. 
As implicações políticas de tudo isso são bem claras: o self humano é tão fluido e fragmentado (o 'sujeito descentrado") e nossas identidades, tão variáveis, incertas e frágeis que não pode haver base de solidariedade e ação coletiva fundamentadas em uma "identidade" social comum (uma classe), em uma experiência comum, em interesses comuns. (WOOD, 1999, p. 13)

Mediante estes preceitos tão fragmentados, Wood (1999) também comenta sobre a impossibilidade de articulação de uma política libertadora fundamentada em uma concepção totalizante, uma frente de oposição unificada. As atitudes de contestação coletiva são ínfimas, pois as iniciativas de resistência foram segmentadas e individualizadas.

Sobre isso, Elias afirma "a humanidade é dividida demais para adotar qualquer medida conjunta contra a aflição dos grupos menos poderosos" (2000, p. p.34). No entanto, Elias (1980, p.30) também nos alerta para o fato de que ideologias, mesmo advindas de conhecimentos científicos, são muitas vezes estéreis por conciliar estruturas racionais com interesses de grupos em busca de uma verdade imutável, tornando-se um sistema de crença e não "uma articulação política libertadora fundamentada em uma concepção totalizante".

Aproximando a análise para as questões da atualidade, podemos analisar um trecho da revista Nova Escola de junho de 2009, que trouxe a matéria da escritora Ana Rita Martins intitulada: A favela como um espaço da cidade. $\mathrm{Na}$ matéria lemos a seguinte declaração:

É importante que os estudantes também percebam que a favela não é um espaço isolado e caracterizado apenas por problemas socioeconômicos e de infraestrutura. Por ser um ambiente multicultural, com pessoas vindas de diferentes lugares do país, esses espaços se tornaram condensadores de cultura. Não à toa, certas manifestações que fazem parte da identidade cultural brasileira, como o samba e o pagode, têm seus maiores expoentes vindos justamente das comunidades. O rap, o funk e mesmo a religiosidade afro-brasileira, como a umbanda e o candomblé, também floresceram lá (MARTINS, 2009, p. 61).

Percebe-se então, no discurso, um incentivo à valorização multicultural presente nas favelas. No entanto, embora seja uma questão importante a ser discutida, notamos que nos conteúdos escolares as temáticas multiculturais ganham protagonismo e os conceitos de coletividade e cidadania são esmaecidos nas pautas escolares. Quando na educação escolar se prioriza o desenvolvimento intelectual, destaca-se em primeiro plano a aprendizagem de conceitos científicos. No entanto, de acordo com o Relatório Jacques Delors, presidido pela Comissão Internacional sobre Educação para o século XXI, da UNESCO (1996):

Qualquer sociedade humana retira a sua coesão de um conjunto de atividades e projetos comuns, mas também, de valores partilhados, que constituem outros tantos aspectos da vontade de viver juntos. Com o decorrer do tempo, estes laços materiais 
tornam-se, na memória individual e coletiva, uma herança cultural, no sentido mais lato do termo, que serve de base aos sentimentos de pertencer àquela comunidade, e de solidariedade [...]. Atualmente, os diferentes modos de socialização estão sujeitos a duras provas, em sociedades ameaçadas pela desorganização e a ruptura dos laços sociais. Os sistemas educativos encontram-se, assim, submetidos a um conjunto de tensões, dado que se trata, concretamente, de respeitar a diversidade dos indivíduos e dos grupos humanos, mantendo, contudo, o princípio da homogeneidade que implica a necessidade de observar regras comuns. Neste aspecto, a educação enfrenta enormes desafios, e depara com uma contradição quase impossível de resolver: por um lado, é acusada de estar na origem de muitas exclusões sociais e de agravar o desmantelamento do tecido social, mas por outro lado, é aquela que se faz apelo, quando se pretende restabelecer algumas das semelhanças essenciais à vida coletiva [...] (DELORS, 1996, p. 51-52).

Diante do exposto acima, concluímos que o novo conceito de cidadania está embasado na diversidade cultural, pois a identidade dos indivíduos não é baseada na igualdade, no que é comum a cultura nacional, no território, na língua de uma nação, mas nas singularidades e especificidades dos grupos. Na diversidade cultural e nova sociabilidade, ocorre a flexibilização das relações, a pluralidade dos sujeitos e uma não padronização dos modos de vida. Nesse sentido, conceitos como diversidade, diferença, pluralidade, heterogeneidade, indicam sinais de aperfeiçoamento de uma civilização.

Com o advento da concepção de diversidade cultural, as lutas políticas adquirem novo formato. Tornam-se então lutas isoladas, na defesa de ideais não unitárias, em que se privilegia a política da identidade e a pluralidade de perspectivas. Em relação aos diferentes grupos existentes, reivindica-se tratamento democrático e tolerante. No entanto, esses grupos não fazem parte de um todo coletivo, mas apenas parte fragmentada de uma sociedade com seus ideais próprios e individualistas.

E a educação, como descrita no Relatório Jacques Delors (1996), tem o dever de respeitar as individualidades, mas ao mesmo tempo, promover a coletividade, promover a solidariedade e estimular o senso de comunidade. Diante dos desafios para conciliação dessas contradições, o sistema educativo desvincula o conhecimento escolar do conhecimento produzido pelo homem genérico como meio de consciência da realidade objetiva. O que resta é o desmantelamento da educação e como consequência, a ausência de coesão e fragmentação da sociedade.

A análise que buscamos empreender permite à compreensão dos elementos que constituíram a sociedade no passado, e como esses fatores foram tidos como essenciais para o desenvolvimento da civilização. Como também, a ausência dos elementos de coesão nas relações sociais, permitiu o predomínio da violência entre os moradores - de Winston Parva - gerando grandes problemas na sociedade. 
Assim, o estudo das questões do passado, nos serve de orientação para compreendermos o nosso presente social e educativo, na busca por respostas para as questões que envolvem a sociedade contemporânea.

\section{Considerações finais}

$\mathrm{Na}$ obra Os estabelecidos e os outsiders de Norbert Elias (2000), verificamos que o elemento promotor de coesão entre os antigos residentes de Winston Parva, eram os laços sociais que mantinham desde longa data. Como também, a apreciação mútua entre os membros do grupo por meio da fofoca elogiosa. Esses fatores, permitia um julgamento de superioridade aos demais e manutenção do status e do poder no interior da comunidade.

Para manter os recém-chegados distantes da comunidade, os estabelecidos os trataram com desprezo, preconceito e humilhação, por meio da fofoca depreciativa. Assim, mantiveram a coesão entre os antigos residentes afastando os recém-chegados do seu convívio. Os outsiders, por sua vez, por não possuírem relações sociais fortalecidas entre eles mesmos, não conseguiam se defender dos ataques que sofriam. O resultado disto é que a nova geração, os mais jovens, não compreendiam o porquê do desprezo que sofriam, e então tornaram-se violentos, perturbadores, vândalos, diante da exclusão que recebiam dos estabelecidos.

Percebe-se então que a coesão entre os membros da comunidade, tornouse elemento fundamental para o sucesso da manutenção de poder do grupo. Como também, a ausência da coesão entre os outsiders permitiu que as fofocas depreciativas alcançassem o seu objetivo.

Na obra História da Civilização na Europa de François Guizot (1907), o historiador defende que para que um povo tornasse civilizado se fazia necessário o aperfeiçoamento da vida civil e o desenvolvimento da vida individual, ou seja, indivíduo e sociedade deveriam caminhar juntos sob a liderança do governante.

Em nossa análise, a sociedade contemporânea muito se distanciou do princípio de coletividade. Há a prevalência das questões individuais em detrimento do coletivo. Assim, a sociedade está fragmentada em diferentes grupos que lutam por ideais que, mesmo lhes sendo comuns, são unitárias e isoladas. Alienando-se dos fatores relativos ao público, que regem a coexistência e inter-relação entre indivíduos, não havendo interesse ou compreensão por questões relacionadas ao comum, para além de uma única bandeira identitária.

\section{REFERÊNCIAS}

BUENO, Sinésio. Dialética da diferença. Revista Educação. v. 36, n. 3, p. 325-331, set./dez. 2013. Disponível em:

https://revistaseletronicas.pucrs.br/ojs/index.php/faced/article/view/15530

Acesso em: 10 jan. 2020. 
COSTA, Célio Juvenal; MENEZES, Sezinando Luís. Norbert Elias e a teoria dos processos civilizadores. Revista HISTEDBR On-line, Campinas, no 53, p. 238-262, out. 2013.

DELORS, Jaques. (Org.) Educação: um tesouro a descobrir. Relatório para a UNESCO da Comissão Internacional sobre Educação para o século XXI. Lisboa: Edições Asa, 1996.

ELIAS, Norbert. Introdução à Sociologia. Braga - PT: Pax. 1980.

ELIAS, Norbert. Os estabelecidos e os outsiders. Rio de Janeiro: Zahar, 2000.

GUIZOT, François. História da Civilização na Europa. Lisboa: Parceria João Maria, 1907, v. 1.

HOBSBAWM, Eric. Sobre história. 2a. Edição. São Paulo: Companhia das Letras, 1998.

MARTINS, Ana Rita. A favela como um espaço da cidade. Revista Nova Escola, n. 223, junho, 2009, p. 61. Disponível em:

https://novaescola.org.br/conteudo/2321/a-favela-como-um-espaco-da-cidade Acesso em: 10 jan. 2020.

OLIVEIRA, Terezinha. Por que retomar François Guizot. Revista Acta Scientiarum, v. 20, n. 1, p. 121-128, 1998.

WOOD, Ellen Meiksins. Introdução. In: WOOD, Ellen Meiksins; FOSTER, John Bellamy (Orgs). Em defesa da História: marxismo e o pós-modernismo. Rio de Janeiro: Jorge Zahar Editor, 1999.

Recebido em: 23 de fevereiro de 2021. Aceito em: 25 de maio de 2021. Publicado em: 30 de junho de 2021. 